\title{
Obezite cerrahisi uygulanan kadın hastaların solunum fonksiyon değişiklikleri
}

\author{
Respiratory function changes in female patients who have undergone obesity surgery
}

Hacer KUZU OKUR, Aziz Bora KARİP, Orhan ARAS, İksan TAŞDELEN, Hasan ALTUN, Kemal MEMIŞOĞLU

\section{ÖZET}

Amaç: Bu çalışmada, obezite cerrahisi uygulanan hastalarda preoperatif ve postoperatif dönemde kilo değişimleri ile birlikte solunum fonksiyonlarında ortaya çıkabilecek değişikliklerin araştırılması amaçland.

Hastalar ve Yöntemler: Retrospektif yapılan bu çalışmada 2013 y1lı ilk üç ayı içinde obezite cerrahisi geçiren tüm hastalar $(n=55)$ içinde dişlama kriterleri olan kronik obstrüktif akciğer hastalı̆̆ 1 , astım, konjestif kalp yetmezliği ve endokrin bozukluklar çalışma dışı bırakıldığında toplam 25 kadın hasta (yaş ortalaması $\pm \mathrm{SD}, 35,7 \pm 7,5$ yıl) çalışmaya dahil edildi. Preoperatif ve postoperatif 6 . aydaki vücut ağırlığ solunum fonksiyon test parametreleri karşılaştırıldı. Operasyona bağlı vücut kitle indeksi değişimi ile solunum fonksiyonlarındaki değişim arasında korelasyon araştırıldı.

Bulgular: Obezite cerrahisi öncesi ve cerrahiden altı ay sonra vücut ağırlığ 1 ve vücut kitle indeksi sırasıly $118,6 \pm 13,8$ kg'dan $90,9 \pm 13,3 \mathrm{~kg}$ 'a ve $43,5 \pm 4,3 \mathrm{~kg} / \mathrm{m}^{2}$ 'den $33,4 \pm 5,1 \mathrm{~kg} / \mathrm{m}^{2}$ 'ye değişti (her ikisi için $\mathrm{p}<0,001$ ). Solunum fonksiyon testindeki tüm parametrelerde preoperatif ve postopetarif 6.ay arasındaki değişiklikler istatistiksel olarak anlamlıydı.

Sonuç: Obezite cerrahisi uygulanan hastaların postoperatif dönemde vücut kitle indeksindeki azalma ile birlikte solunum fonksiyon test parametrelerinde iyileşme görüldü.

Anahtar kelimeler: Obezite, Pulmoner fonksiyon, Spirometrik test, Obezite cerrahisi, Sleeve gastrektomi, Vücut kitle indeksi

Hacer Kuzu Okur (西)

Göğüs Hastalıkları Kliniği, Fatih Sultan Mehmet Ĕ̌itim ve Araştırma

Hastanesi, Istanbul, Türkiye

e-mail:hacerkuzu@hotmail.com

Aziz Bora Karip, Orhan Aras, İksan Taşdelen, Hasan Altun, Kemal Memişoğlu

Genel Cerrahi Kliniği, Fatih Sultan Mehmet Eğitim ve Araştıma

Hastanesi, İstanbul, Türkiye

Gönderilme/Submitted: 24.10 .2013

Kabul/Accepted: 20.11.2013

\begin{abstract}
Objectives: This study aims to investigate the changes in respiratory functions, which can occur together with weight changes in the preoperative and postoperative period in patients who have undergone obesity surgery.

Patients and Methods: In this retrospective study all patients $(n=55)$ who had undergone obesity surgery during the first three months of 2013 were examined and 25 female patients (mean age $\pm \mathrm{SD}, 35.7 \pm 7.5$ year) who met the required criteria (lack of chronic obstructive pulmonary disease, asthma, congestive heart failure and endocrine disorders) were included. A comparison was made between the preoperative and postoperative 6th month body weight, body mass index and respiratory function test parameters.

Results: Mean weight measured in the preoperative and 6th postoperative months was $118.6 \pm 13.8$ and $90.9 \pm 13.3$ respectively while body mass index was $43.5 \pm 4.3$ and $33.4 \pm 5.1 \mathrm{~kg} / \mathrm{m}^{2}$, respectively $(\mathrm{p}<0.001$ for both). Changes in all the pulmonary function test parameters between the preoperative to the 6th month postoperative period were also significant.

Conclusion: Patients who had undergone obesity surgery, had a decrease in body mass index. In addition, they showed improvement in the respiratory function test parameters in the postoperative period.
\end{abstract}

Key words: Obesity, Respiratory functions, Spirometry test, Obesity surgery, Sleeve gastrectomy, Body mass index

\section{Giriş}

Obezite modern dünyada giderek artan önemli halk sağlığ1 sorunlarından birisidir. Dünya Sağlık Örgütü (DSÖ), obeziteyi sağlığı bozacak ölçüde vücutta yă̆ birikmesi olarak tanımlamıştır [1]. Fazla kiloluluk ve obezite prevalansı DSÖ tarafindan yapılan MONICA çalışmasında erkeklerde \%15, kadınlarda \%22 bulunmuştur [2]. DSÖ, 2003 yılında, tüm dünyada, yaklaşık 300 milyon obez olduğunu, 2008 yılı rakamlarına göre ise 1,4 milyar kilolu kişiden erkek obezlerin 200 milyon, kadın obezlerin 300 milyon olduğunu bildirilmiştir. Aradan geçen beş senede görülen artış korkutucudur [3]. 
2013 yılı Sağlık Bakanlığı verilerine göre, Türkiye Beslenme ve Sağlık Araştırması sonuçlarında obezite sıklığ1 19 yaş ve üzerinde $\% 30,3$ 'dür. Bu oran erkeklerde $\% 20,5$, kadınlarda ise \%41 olarak bulunmuş, ayrıca fazla kilolu olma oranı \%34,6 olarak bildirilmiştir [4].

Kilo artışı ile birçok sistemin etkilendiği ve obezite ile mortalite ve morbidite oranının arttığ 1 bilinmektedir. Diabetes mellitus, hipertansiyon, koroner kalp hastalığ1, hiperlipidemi, obstrüktif uyku apnesi, obezite hipoventilasyon sendromu, astım ve gastroözofageal reflünün obezite ile ilişkili olduğu bilinmektedir [5]. Obezite akciğer fonksiyonlarını birçok yönden etkilemektedir. Boyun, üst hava yolları, göğüs duvarı ve göbek etrafında yağ depolanması solunum sisteminin mekanik fonsiyonunu bozar. Obezlerdeki havayolu ve solunum sistemi direncindeki artmanın vücut kitle indeksi (VKI) ile negatif korelasyon gösterdiği pek çok çalışmada gösterilmiştir. Obezlerde artmış akciğer ve solunum sistemi direncinin temel nedeni akciğer hacimlerindeki azalma olduğu düşünülmektedir [6]. Akciğer haciminde ortaya çıkan bu azalmanın obezitenin ortadan kaldırılmasıyla değişikliğe uğrayıp uğramadığı, kalıcı bir hacim azalması yaratıp yaratmadığına ait çeşitli çalışmalar bulunmaktadır [7].

Obezite tedavisinde, diyet, egzersiz, davranışsal değişiklikler öncelikli olarak denenmektedir. Obezite hastaları pek çok diyet programını bilmelerine ve uygulamalarına rağmen kilo veremeyen hastalardır. Obezite cerrahisi ülkemizde birçok merkezde farklı cerrahi yöntemler kullanılarak uygulanabilmektedir. Cerrahi yöntemler içinde yer alan sleeve gastrektomi kilo vermede oldukça iyi sonuçların alındığı, morbiditenin \%1-2, mortalitenin $\% 1$ oranında olduğu bir teknik olarak literatürde yer almaktadır [8].

$\mathrm{Bu}$ çalışmada, obezite cerrahisi uygulanan hastaların hem cerrahi öncesi ve hem de cerrrahi sonrasi kilo vermelerinin ardından solunum fonsiyon test sonuçları değerlendirilmiş ve solunum fonksiyonlarında değişim olup olmadığ 1 incelenmiştir.

\section{Hastalar ve Yöntem}

\section{Çalışma grubu}

$\mathrm{Bu}$ çalışma retrospektif olarak planlanmıştır. Çalışmaya Fatih Sultan Mehmet Eğitim ve Araştırma Hastanesi Genel Cerrahi bölümüne obezite cerrahisi uygulanmak üzere 1 Ocak 2013 ve 31 Mart 2013 arasında başvuran 55 hasta ön değerlendirmeye alınmıştır. Bu hastalar içinden bronşiyal astım, kronik obstrüktif akciğer hastalığı, solunum sistemini etkileyecek herhangi bir meslek veya çevresel faktöre maruz kalma öyküsü olması, konjestif kalp yetmezliği, endokrinolojik patoloji, böbrek yetmezliği, psikiyatrik hastalık öyküsü olması, hipoventilasyon sendromu, uyku apne sendromu varlığını düşündürecek horlama, uykuda nefes durması, gündüz aşırı uyku hali olması gibi bulguların bulunması dışlama kriterleri olarak değerlendirilmiş ve toplam 25 kadın hasta (yaş ortalaması \pm SD, 35,7 7 7,5 yı1; aralık, $\left.18-50 \mathrm{yıl} ; \mathrm{VKI}, \geq 35 \mathrm{~kg} / \mathrm{m}^{2}\right)$ çalışmaya ve son analize dahil edilmiştir.

Hastaların preoperatif ve postoperatif kiloları hassas dijital tartı ile ölçülmüş ve kilo ve boy ölçümleri kaydedilmiş ve VKI'leri hesaplanmıştır. Obezite değerlendirmesinde en sık kullanılan ve vücut yağ miktarı ile iyi korelasyonu olan ölçü VKİ'dir. VKİ, bireyin ağırlığının boyunun karesine bölünmesiyle hesaplanır ve birimi $\mathrm{kg} / \mathrm{m}^{2}$ dir. DSÖ tarafindan belirlenen uluslararası sinıflandırmaya göre VKİ $\geq 30$ obez olarak tanımlanmıştır [9]. Olguların sigara alışkanlığı (paket/ yıl), solunum semptomları, biyokimyasal kan değerleri, oksijen satürasyonu nabız oksimetre ile ölçüldü, hastalık ve ilaç kullanma öyküleri kaydedildi. Tüm olgulara operasyon öncesi endokrinoloji ve psikiyatri muayenesi yapıldı. Tüm olgulara obezite cerrahisi olarak sleeve gastrektomi operasyonu yapıldı. Operasyon sonrasinda, hastalara beslenme programı uygulamaları ve egzersiz yapmaları önerildi. Cerrahi sonrası olguların 1.ay, 3. ay ve 6.ayda kontrolleri yapıldı. Çalışmaya alınan hastalara değerlendirme parametreleri hakkında bilgi verilerek onayları alındı. Preoperatif solunum fonksiyon testi değerleri ve postoperatif 6. ay testleri karşılaştırıldı.

\section{Solunum fonksiyon testleri}

Solunum fonksiyon testleri (SFT) spirometrik yöntemle (Vitalograph spirometer Zan, Messgeraete GmbH Germany) yapıld1. Yapılacak test hastalara anlatıldı ve gösterildi. Ölçüm öncesi hastalar en az 15 dakika oturtuldu dinlendirildi ve test hastalar rahat oturur pozisyonunda iken yapıldı. Buruna klip takılarak burun kapatıldı. Ağızlık, diş ve dudaklar arasına yerleştirildikten sonra ağızlık içinden hava kaçağı olmadan hastalara rahat bir şekilde soluk alıp vermesi söylendi. Sonra derin bir inspiryum yaptırılarak ardından hızla ve olabildiğince güçlü ekspiryum yapılması istendi ve ardından yine derin bir inspiryum yaptırılarak spirometrik test tamamland. Bu uygulama $3 \mathrm{kez}$ tekrarlanarak spirometrenin standardizasyonu kılavuzuna göre kabul edilebilirlik ve tekrarlanılabilirlik kriterine uygun olan test kabul edildi. Zorlu vital kapasite (forced vital capacity $[\mathrm{FVC}]$ ) ve birinci saniyedeki zorlu ekspirasyon hacmi (forced expiratory volume in 1-s [FEV1]) değerileri ölçüldü ve kayıt edildi. Hava akım k1sıtlamas1 FEV1/FVC oranı ile belirlendi. Hava akımı k1sıtlanmas1 FEV1/FVC oran1 \%70 den az ise obstrüksiyon, $\% 80$ den fazla ise ve FVC oranın normal ya da artmış olması restriksiyon olarak tanımlandı. Maksimum ekspirasyon akım hızı MEF \%75, MEF \%50 ve MEF \%2575 olarak ölçüldü. 


\section{Istatistiksel değerlendirme}

Verilerin istatistiksel değerlendirmesi SPSS 16.00 paket program kullanılarak yapıldı. Değişkenlerin analizi için eşlendirilmiş t-testi kullanıldı. Solunum fonksiyonları ve VKİ arasındaki ilişki Pearson's korelasyon analizi ile değerlendirildi. Tüm istatistiksel değerlendirmelerde $p<0,05$ değeri anlamlı olarak kabul edildi.

\section{Bulgular}

Preoperatif tüm olguların nabız oksimetre ile oksijen satürasyonu ortalamas1 $\% 96$ olarak bulundu. Sigara içen 10 hastanın sigara maruziyeti ortalama 7 paket/y1l idi. 7 hasta hiç sigara içmemiş, 8 hasta ise sigarayı içip, bırakmıştı. Hipertansiyon sadece 4 olguda vardi. Postoperatif 1 olguda yara yeri enfeksiyonu gelişti. Olguların obezite cerrahisi öncesi ve cerrahinin 6.ayındaki kilo ve VKİ değerleri Tablo I'de verilmiştir.

Postoperatif 6. ay kontrollerinde tüm olguların kilolarında azalma saptandı. Kilo kaybının en az $23 \mathrm{~kg}$ en fazla $32 \mathrm{~kg}$ olduğu bulundu. VKİ'inin tüm olgularda azaldığ 1 , ayrıca, VKI'de en az 8,3 ve en fazla $11,9^{\prime}$ luk değişiklik olduğu tespit edildi. Obez olguların preoperative FVC, FEV1, FEV1/FVC, MEF50, MEF75 ve MEF25-75 değerleri normal sınırlarda olmasına rağmen postoperatif 6 . ay ölçümündeki SFT değiş̧ikliği mevcuttu (Tablo II). Cerrahi tedavi sonucu VKI'de meydana gelen değişikliğin solunum fonksiyonlarında bir değişime neden olup olmadığını araştırmak için cerrahi operasyon öncesi ve sonrası VKI değişimi ile FVC değişimi arasında korelasyon analizi yapıldı. İki parametre arasında anlamlı ilişki saptandı.

\section{Tartışma}

$\mathrm{Bu}$ çalışmada, obezite cerrahisi uygulanan hastalarda, preoperatif dönemde normal sınırlar içerisinde olan solunum fonksiyonlarının, postoperatif dönemde VKI'deki değişimle birlikte belirgin artı̧̧ gösterdiği saptanmıştır. Biz çalışmamızda obezitede \%23 lük azalma saptadık, bu azalma ile birlikte FVC, FEV1, MEF75, MEF50 ve MEF2575 değerlerinde istatistiksel olarak anlamlı artış olduğu görüldü. Guimares ve ark., 36 morbid obez hastada obezite

Tablo I. Obezite cerrahisi geçiren kadınlarda $(n=25)$ cerrahi öncesi ve sonrası kilo ve vücut kitle indeksi değişimleri.

\begin{tabular}{lccc}
\hline & Preoperatif & Postoperatif 6. Ay & $\mathrm{P}^{*}$ \\
Kilo, $\mathrm{kg}$ & $118,64 \pm 13,85$ & $90,88 \pm 13,34$ & $<0,001$ \\
VKİ, $\mathrm{kg} / \mathrm{m}^{2}$ & $43,52 \pm 4,35$ & $33,36 \pm 5,12$ & $<0,001$ \\
\hline
\end{tabular}

Kısaltmalar: VKİ: vücut kitle indeksi. *Eşlendirilmiş t-testi
Tablo II. Obezite cerrahisi geçiren kadınlarda $(n=25)$ cerrahi öncesi ve sonrası solunum fonksiyon testi parametrelerindeki değişimler (ortalama $\pm \mathrm{SD}$ ).

\begin{tabular}{lccc}
\hline & Preoperatif & Postoperatif 6. Ay & P* \\
\hline FVC, L & $3,28 \pm 0,54$ & $3,50 \pm 0,53$ & $<0,001$ \\
FEV1, L & $2,88 \pm 0,44$ & $3,05 \pm 0,42$ & 0,001 \\
FEV1/FVC, \% & $87,92 \pm 5,70$ & $87,44 \pm 5,48$ & 0,004 \\
MEF 75, L/s & $5,56 \pm 1,04$ & $5,98 \pm 0,69$ & 0,001 \\
MEF 50, L/s & $4,41 \pm 1,21$ & $4,23 \pm 0,96$ & $<0,001$ \\
MEF 25-75, L/s & $3,32 \pm 1,09$ & $3,65 \pm 0,78$ & $<0,001$ \\
\hline
\end{tabular}

Kisaltmalar: VFC: zorlu vital kapasite, FEV1: 1. saniyedeki zorlu ekspirasyon hacmi, MEF: maksimum ekspirasyon akım hızı. *Eşlendirilmiş t-testi

cerrahisi sonrası 6 . ayda yaptıkları ölçümlerde, total akciğer kapasitesinde, FEV1 ve FVC'de artış bulmuşlardır [7]. Ancak bu çalışmada preoperatif restriksiyonu olan hastalarda çalışılmış olması bizim çalışmamıza göre farklılık yaratmaktadır. Normal sınırlar içerisindeki solunum fonksiyonlarında bile iyileşmenin olmasını göstermemizin, obezitenin solunum fonksiyonları üzerine yaptığı olumsuz etkiler açısından dikkate değer olduğunu düşünmekteyiz.

VKİ deki azalma ile birlikte MEF75, MEF50 ve MEF25-75 değerlerinde istatistiksel olarak anlamlı artma olduğunu bulduk. Obezitenin derecesinin artmasiyla periferik hava yollarında ekspiratuar basınç parametrelerinde azalmaların olabileceği bilinmektedir [10]. Sütbeyaz ve ark. obezlerde yaptıkları solunum fonksiyon testlerinde obez olmayanlara gore FVC, FEV1, MEF50, MEF25-75 değerlerinde VKİ ile negatif korelasyon olduğunu bulmuşlardır. Akciğer hastalığı olmaksızın solunum fonksiyonlarında görülen bozulmaların obezitenin şiddeti ile arttığını vurgulamışlardır [11].

Obezlerde kilo kaybı ile birlikte akciğer fonksiyonlarında iyileşmelerin olduğu pek çok çalışmada gösterilmiştir $[12,13]$. $\mathrm{Bu}$ iyileşme, kilo kaybının obezitede kitle etkisini azaltmasıyla açıklanmıştır. Son yıllarda yapılmış prospektif bir çalışmada obezite cerrahisi ile kilo kaybeden obezlerin aerobik kapasitelerindeki iyileşmenin etkisini vurgulamaktadır [14]. Çalışmamızda, preoperatif VKİ ortalaması $43,52 \mathrm{~kg} / \mathrm{m}^{2}$ olan olgularda, postoperatif kilo kaybi ile bu oranın 33,36 $\mathrm{kg} / \mathrm{m}^{2}$ 'ye gerilediği görülmüştür. Kilo kaybı, VKİ değerinde $\% 23$ 'lük azalma sağlamasına rağmen, hastalar halen obezite sinırlarındadır. Preoperatif FEV1/FVC oranında kilo kaybına rağmen, postoperatif dönemde değişiklik olmadığ 1 görülmüştür. Silva ve ark.nın yaptığı bir çalışmada da 


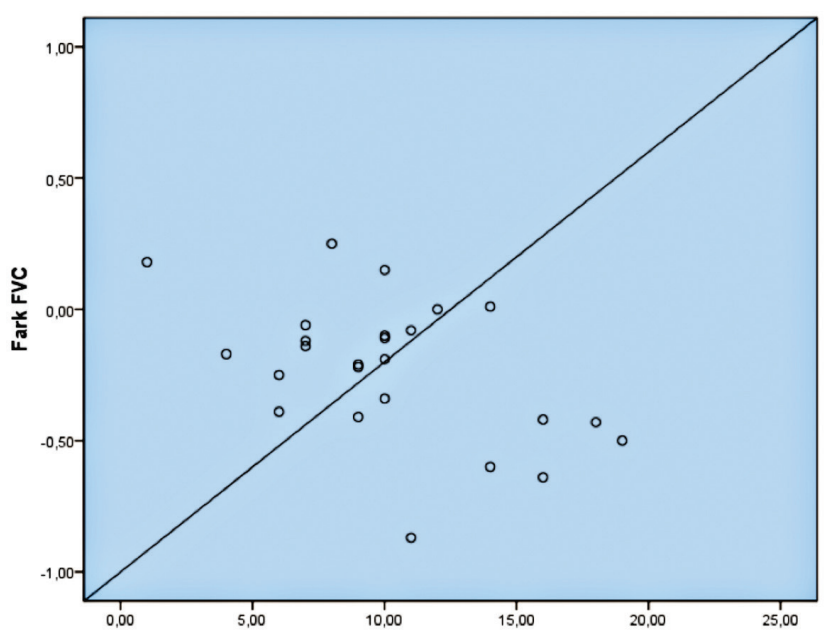

Şekil 1. Obezite cerrahisi öncesi ve sonrası vücut kitle indeksi (VKİ) değişimi ile $\mathrm{FVC}$ değişimi arasındaki ilişki (Pearson $\mathrm{R}=-0,494 ; \mathrm{p}=0,012$ ).

hastalar postoperatif 14 ve 30 'uncu günlerde değerlendirilmiş FVC, FEV1 ve MEF değerlerinde herhangi bir değişiklik bildirilmemiştir. Çalışmada yeterli kilo vermenin sağlanamadığı, dolayısıyla bu değerlerin de buna bağlı olarak değişmediği düşünülmüştür [15].

Çalışmamızda, solunum fonksiyonlarını değerlendirmek için spirometri tekniğinden yararlanılmış, hastaların uyanıklık oksijen düzeylerinin normal olması nedeniyle kan gazı ölçümüne gerek duyulmamıştır. Spirometri oldukça kullanışlı, rahatsızlık uyandırmayan ve dünyada kullanımı kabul edilmiş bir metotdur. Crapo ve ark'ları morbid obezlerin preoperatif değerlendirmesinde spirometrinin ucuz ve güvenli olmasının yanında postoperatif solunumsal komplikasyon riskini tanımlamada da önemini vurgulamıştır [16]. Dolayısıyla obeziteye komorbid bir hastalık durumu olmayan obezite cerrahisine aday hastalarda, spirometri kullanımı uygun bir tetkik yöntemi olarak düşünmekteyiz.

Çalışmadaki hastaların tamamının kadın olması, genel olarak morbid obezitenin kadınlarda daha yüksek oranlarda görülmesiyle ilişkilendirilmiştir [17]. Kolitkin ve ark., çalışmalarında obezite cerrahisine giden hastalarda kadınların daha yüksek oranda olduğunu göstermiş̧lerdir. Bu durum kadınların obeziteden kurtulabilmek için daha fazla cerrahi yöntemlere başvurduklarını ya da kadınlarda morbid obezitenin daha yüksek oranlarda görüldügünü düşündürmektedir [18].

Obezite nedeniyle sleeve gastrektomi cerrahisi operasyon sonrası Türk popülasyonunda yapılmış solunum fonsiyonlarını değerlendiren çalışma yoktur. Bizim çalışmamız bu anlamda literature katkı sağlamaktadır. Vaka sayımızın az olması, postoperatif uzun dönem etkinliğinin değerlendirilmemiş olması çalışmamızın kısıtlılıklarıdır. Obezitenin cerrahi yöntemlerle tedavi edilmesi birçok organ sistemine getirdiği yararla birlikte solunum fonsiyonları üzerine de olumlu katkı sağlamaktadır.

\section{Çıkar Çatışması}

Yazarlar herhangi bir çıkar çatışması bildirmemişırerdir.

\section{Kaynaklar}

1. Obesity: preventing and managing the global epidemic: report of aWHO consultation. WHO technical report series; 894. Geneva: WHO, 1999 .

2. WHO MONICA project: Risk factors. International Epidemiology 1888; 18:46-55.

3. Deitel M. Overweight and obesity worldwide now estimated to involve 1.7 billion people. Obes Surg 2003;13:329-30. doi:10.1381/ 096089203765887598

4. T.C. Sağlık Bakanlığı Türkiye Halk Sağlığı Kurumu Birinci basamak hekimler için Obezite ile Mücadele El Kitabı. Ankara: Anıl Matbaac1lik, 2013:22.

5. Eeg-Olofsson K, Cederholm J, Nilsson PM, et al. Risk of cardiovascular disease and mortality in overweight and obese patients with type 2 diabetes: an observational study in 13,087 patients. Diabetologia 2009;52:65-73. doi: 10.1007/s00125-008-1190-x

6. Kopelman PG. Clinical complications of obesity. Clin Endocrinol Metab 1984;13:613-34.

7. Guimarães C, Martins MV, Moutinho Dos Santos J. Pulmonary function tests in obese people candidate to bariatric surgery. Rev Port Pneumol $2012 ; 18: 115-9$. doi: 10.1016/j.rppneu.2012.01.005

8. Sarkhosh K, Birch DW, Sharma A, Karmali S. Complications associated with laparoscopic sleeve gastrectomy for morbid obesity: a surgeon's guide. Can J Surg 2013;56:347-52. doi: 10.1503/cjs.033511

9. WHO Expert Committee. Physical status: the use and interpretation of anthropometry. WHO Technical Report Series no 854. Geneva: WHO, 1885.

10. Koening SM.Pulmonary complications of obesity. AM J Epidemiol 2001;321:249-79.

11. Sütbeyaz ST, İbrahimoğlu F, Sezer N, et al. Obez bireylerde vücut yağ dağılımının pulmoner fonksiyon ve solunum kasları kuvveti üzerine etkileri. Türk Fiz Tip Rehab Derg 2006;52:15-8.

12. Mailo C, Mohamed EI, Carbonelli MG. Body composition and respiratory function. Acta Diabetol 2003;40:32-8.

13. Bottai M, Pistelli F, Pede F D, et al. Longitudinal changes of body mass index, spirometry and diffusion in a general population. Eur Respir J 2002;20:665-73. doi: 10.1183/09031936.02.01282001

14. De Souza SA, Faintuch J, Sant'anna AF. Effect of weight loss on aerobic capacity in patients with severe obesity before and after bariatric surgery. Obes Surg 2010;20:871-5. doi: 10.1007/s11695-0100109-z

15. Silva AMO, Boin IFS, Pareja JC, et al. - Análise da função respiratória em pacientes obesos submetidos à operação FobiCapella. Rev Col Bras Cir 2007;34:314-20.

16. Crapo RO, Kelly TM, Elliot CG, et al. Spirometry as a preoperative screening test in morbidly obese patients. Surgery 1986;99:763-7.

17. World Health Organization. Obesity and Overweight FactSheet No: 311. Geneva: WHO. Available at URL: http://who.int/mediacentre/ factsheets/fs3117en/print. Accessed: 10.10.2013.

18. Kolotkin RL, Crosby RD, Willians GR, et al. The relationship between health-related quality of life and weight loss. Obes Res 2001;9:564-71. 